\title{
Yenidoğan Yoğun Bakım Ünitesinde Gelişen Sağlık Bakım İlişkili Enfeksiyonlar: Son Altı Yılın Değerlendirilmesi
}

\author{
Healthcare-Associated Infections in the Neonatal Intensive Care \\ Unit: Review of the Last Six Years
}

Meltem KARABAY ${ }^{1}$, Gülsüm KAYA², Ertuğrul GÜÇLÜ³ ${ }^{3}$ Aziz ÖĞ̈̈TLÜ³ ${ }^{3}$ Oğuz KARABAY³, ỉbrahim CANER

'Sakarya Üniversitesi Tıp Fakültesi, Çocuk Sağlığı ve Hastalıkları Anabilim Dalı, Neonatoloji Bilim Dalı, Sakarya, Türkiye

${ }^{2}$ Sakarya Üniversitesi Eğitim ve Araştırma Hastanesi, Enfeksiyon Kontrol Komitesi, Sakarya, Türkiye

${ }^{3}$ Sakarya Üniversitesi Tıp Fakültesi, Enfeksiyon Hastalıkları ve Klinik Mikrobiyoloji, Sakarya, Türkiye

\section{Öz}

Amaç: Sağlık bakım ilişkili enfeksiyon (SBiE)'ların yenidoğan yoğun bakım ünite (YYBÜ)'lerinde önemli morbidite ve mortalite nedenidir. Bu çalışmada altı yıllık zaman diliminde YYBÜ'deki SBiE’'ler ve ilişkili faktörlerin değerlendirilmesi amaçlandı.

Gereç ve Yöntemler: Çalışma YYBÜ'de 1 Ocak 2013-31 Aralık 2018 tarihleri arasında yapıldı. YYBÜ'de gelişen SBIE'ler retrospektif olarak değerlendirildi. YYBÜ günlük aktif sürveyansla takip edildi. SBiE tanısı Center for Disease Control and Prevention (CDC) kriterlerine göre konuldu. YYBÜ'de yatan hasta sayıSı, hasta günü, tespit edilen SBIE, invaziv araç kullanım oranı ve tespit edilen patojenler değerlendirildi.

Bulgular: Bu araştırmada 2196 hasta, 33652 hasta günü, 4157 ventilatör günü, 3343 umbilikal kateter günü, 5210 santral venöz kateter günü ve 92 üriner kateter günü değerlendirildi. SBIE hızı \%4.78 (105/2196) ve insidans dansitesi \%॰3.12 (105/33652)'di. SBIE dağılımları değerlendirildiğinde; SBiE'nin 101 (\%96.1)'i kan dolaşımı enfeksiyonu (KDE), ikisi (\%1.90) pnömoni, biri (\%0.95) merkezi sinir sistemi enfeksiyonu ve biri (\%0.95) yumuşak doku enfeksiyonuydu. SBIE sıklı̆ı 2500 gr dan büyük bebeklerde daha az (\%1.02) iken, 751-1000 gr arası bebeklerde daha fazla (\%23.95)'di (p<0.001). Etken dağılımına göre; \%59.0 (62/105)'u gram negatif bakteri (GNB), \%41.0 (43/105)'i gram pozitif bakteri (GPB) kaynaklıydı. En sık izole edilen GNB’ler; Klebsiella spp. (\%34.2), Enterobacter spp. (\%12.3) ve en sık izole edilen GPB'ler; Stafilokoklardı (\%37.0). İnvaziv araç ilişkili enfeksiyon hızları değerlendirildiğinde; santral venöz kateter ilişkili KDE hızı \% 0.95, umbilikal kateter ilişkili KDE hızı \%॰2.09'du.

Sonuç: SBIE'ler içinde en sık görüleni KDE'di. İnvaziv girişimler ve düşük doğum ağırlığı enfeksiyon riskini artıran faktörler olarak saptandı. SBiE gelişme sıklığı bebek doğum ağırlığı ile ters orantılıydı. Düşük doğum ağırlıklı bebeklerde daha hassas enfeksiyon kontrol önlemlerinin gerektiği düşünüldü.

Anahtar Sözcükler: Kan dolașımı enfeksiyonları, Sağlık bakım ilişkili enfeksiyonlar, Yenidoğan yoğun bakım ünitesi

(1)

KARABAY M : 0000-0001-7105-7176 KAYA G : :0000-0003-2517-5512 GÜLCÜE $\quad: 0000-0003-2860-2831$ OGUTUA :0000-0003-3840-4038 $\begin{array}{lll}\text { KARABAY O } & : 0000-0003-1514-1685 \\ \text { CANERI } & : 0000-0002-6756-122 X\end{array}$
Çıkar Çatışması / Conflict of Interest: Tüm yazarlar adına, sorumlu yazar çıkar çatışması olmadığını belirtir.

Etik Kurul Onayı / Ethics Committee Approval: Bu çalıșmada ulusal ve uluslararası etik kurallara uyulmuștur. Çalıșma için etik 02/11/2017 tarih ve 71522473/050.01.04/208 sayı numarası ile alındı.

Yazarların katkısı / Contribution of the Authors: KARABAY M: Araştırma ve/veya makalenin hipotezini veya fikrini olușturan, Sonuçlara ulașmak için planlama/ metodoloji belirleme,Hasta takibinde sorumluluk almak, ilgili biyolojik malzemelerin toplanması, veri yönetimi ve raporlama, deneylerin yürütülmesi,Sonuçların mantıksal olarak Yorumlanması ve sonuçlandırıması,Çalıșmanın bütününün veya önemli bölümlerinin yazımında sorumluluk almak, Yazım ve dilbilgisi dıșında bilimsel olarak gönderilmeden önce makaleyi gözden geçirme, KAYA G: Araștırma/çalıșmanın sorumluluğunu üstlenmek, ilerlemenin seyrini denetlemek, Araștırma/çalıșanın sorumluluğunu üstlenmek, ilerlemenin seyrini denetlemek. Hasta takibinde sorumluluk almak, ilgili biyolojik malzemelerin toplanması, veri yönetimi ve raporlama, deneylerin yürütülmesi,Yazım ve dilbilgisi dıșında bilimsel olarak gönderilmeden önce makaleyi gözden geçirme. GÜÇLÜ E:Sonuçların mantıksal olarak Yorumlanması ve sonuçlandırıması, Çalıșmanın bütününün veya önemli bölümlerinin yazımında sorumluluk almak, ÖGÜTLÜ A: Araștırma/çalıșmanın sorumluluğunu üstlenmek, ve sonuçlandirıması, Çalıșmanın bütününün veya önemli bölümlerinin yazımında sorumluluk almak, OGUTLU A: Araştı̈ma/çalıșmanın sorumluluğunu üstlenmek,
ilerlemenin seyrini denetlemek, Çalıșma için gerekli literatür taramasında sorumluluk almak,Çalısmanın bütününün veya önemli bölümlerinin yazımında sorumluluk almak, KARABAY O: Sonuçlara ulaşmak için planlama/metodoloji belirleme, Çalıșmanın bütününün veya önemli bölümlerinin yazımında sorumluluk almak, Yazım ve dilbilgisi dışında bilimsel olarak gönderilmeden önce makaleyi gözden geçirme. CANER $\boldsymbol{i}$ : Sonuçlara ulaşmak için planlama/metodoloji belirleme,Çalışma için gerekli literatür taramasında sorumluluk almak,

Atıf yazım şekli / How to cite : Karabay M, Kaya G, Güçlü E, Öğütlü A, Karabay O, Caner I. Yenidoğan Yoğun Bakım Ünitesinde Gelişen Sağlık Bakım Illişkili Enfeksiyonlar: Son Altı Yllın Değerlendirilmesi. Türkiye Çocuk Hast Derg 2021;15:87-92.

Ek bilgi / Additional information: Bu çallşma 29 Kasım-3 Aralık 2017 tarihleri arasında gerçekleșen 10.Uluslararası Sterilizasyon Dezenfeksiyon Kongre-sinde poster bildiri olarak sunulmuştur (PS-074).
Yazışma Adresi / Correspondence Address:

\section{Meltem KARABAY}

Sakarya Üniversitesi Tıp Fakültesi,

Çocuk Sağlığı ve Hastalıkları Anabilim Dalı, Sakarya, Türkiye

E-posta: meltemkarabay@yahoo.com
Geliș tarihi / Received : :27.07.2019 Kabul tarihi / Accepted : 14.01.2020 Elektronik yayın tarihi : 12.03 .2020 Online published

DOI: $10.12956 /$ tchd.597635 


\section{ABSTRACT}

Objective: Healthcare related infections (HCRI) are important causes of morbidity and mortality in neonatal intensive care units (NICUs). The aim of this study was to evaluate HCRI and related factors in the ICU over a six-year period.

Material and Methods: The study was conducted in the NICU between 1 January 2013 and 31 December 2018. NICU-derived HCRI was evaluated retrospectively. The NICU was followed by daily active surveillance. HCRI was diagnosed according to the Center for Disease Control (CDC) criteria. The number of inpatients, patient days, HCRI, invasive device use and pathogens were evaluated.

Results: A total of 2196 patients, 33652 patient days, 4157 ventilator days, 3343 umbilical catheter days, 5210 central venous catheter days, and 92 urinary catheter days were observed. The HCRI rate was 4.78\% (105/2196) and the incidence density was 3.12\% (105/33652). When evaluated according to HCRI, 101 (96.1\%) bloodstream infections (BSI), two (1,90\%) pneumonia, one (0.95\%) central nervous system infection and one (0.95\%) soft tissue infection were detected. The incidence of HCRI was less (1.02\%) in infants older than 2500 grams, whereas it was higher in infants between 751-1000 grams (23.95\%) ( $p<0.001)$. According to the distribution of bacteria, 59.0\% (62/105) of them were from gram-negative bacteria (GNB) and $41.0 \%$ (43/105) of them were from gram-positive bacteria (GPB). Commonly isolated GNBs were Klebsiella spp. (34.2\%) and Enterobacter spp. (12.3\%) whereas the most frequently isolated GPBs were Staphylococci (37.0\%). When invasive devices-related infection rates were evaluated; The central venous catheter-related BSI rate was $0.95 \%$, and the umbilical catheter-related BSI rate was $2.09 \%$.

Conclusion: The most common HCRI was BSI in our hospital. Invasive procedures and low birth weight were the factors that increased the risk of infection. The incidence of $\mathrm{HCRI}$ was inversely related to birth weight. It was thought that more sensitive infection control measures were needed in low birth weight infants.

Key Words: Bloodstream infections, Healthcare-associated infections, Neonatal intensive care unit

\section{GiRiş}

Günümüzde tanı ve tedavideki gelişmeler, yapılan gerekli müdahaleler sonucu yenidoğan yoğun bakım ünite (YYBÜ)'lerinde yatan bebeklerin yaşama olasılığını eskiye oranla daha da artmıştır(1). YYBÜ gibi kritik alanlarda izlenen preterm yenidoğanlarda enfeksiyon olasılığı yüksektir (2). Çünkü bu bebeklerde immün sistem yeterince gelişmemiştir. Ayrıca invaziv girişimlerin sık uygulanmasıda sağlık bakım ilişkili enfeksiyon (SBIE)'ların sıklığını yükseltir $(3,4)$. SBíE'ler bu bebekler için önemli bir morbidite ve mortalite nedeni olup hastanede kalış süresini ve maliyetleri arttırır $(3,5,6)$.

Enfeksiyon kontrolüne yönelik alınan tüm önlemlere rağmen, araștırmalarda YYBÜ'lerinde SBIE oranları \%8-74 arasında bildirilmektedir (2). YYBÜ'lerinde en sık görülen enfeksiyonlar; kan dolaşım enfeksiyonları (KDE), pnömoni ve üriner sistem enfeksiyonlarıdır (7). SBIE için risk faktörleri içinde; prematürite, düşük doğum ağırlığı, mekanik ventilasyon uygulanması, santral venöz kateter kullanımı, geniş spektrumlu antibiyotiklerin uygunsuz kullanımı ve uzun süre hastanede yatma sayılabilir (8). SBIE'nin insidansı üniteden üniteye farklılıklar göstermektedir. Beslenme ve ilaç uygulamaları nedeniyle yerleştirilen santral venöz kateterler ve özellikle periferik yerleștirilen merkezi kateterler, kateter ilişkili kan dolașımı enfeksiyonlarına neden olmaktadır. Bu enfeksiyonlar YYBÜ'lerinde en sık görülen enfeksiyonlardandır $(9,13,16)$.

YYBÜ etkeni bakteriler daha dirençli olabilmektedir. YYBÜ'lerinde SBIE etkeni olarak Gram negatif bakterilerden (GNB) Klebsiella pneumoniae ve Escherichia coli, Gram pozitif bakterilerden (GPB) Koagülaz negatif stafilokoklar (KNS) ve Staphylococcus aureus dikkati çekmektedir $(10,11)$.
Bu çalışmada 2013-2018 yılları arasında hastanemizin YYBÜ'de gelişen SBIE'lerin değerlendirmesi amaçlandı.

\section{GEREÇ ve YÖNTEMLER}

Bu araştırma YYBÜ'de 01 Ocak 2013 - 31 Aralık 2018 tarihleri arasındaki altı yıllık verilerden oluşturuldu. Araștırmanın etik onamı 02/11/2017 tarih ve 71522473/050.01.04/208 sayı numarası ile alındı.

Araştırmanın yapıldığı hastane üçüncü basamak bir hastane olup, YYBÜ altısı ikinci düzey, 13'ü üçüncü düzey olmak üzere toplam 19 küvöze sahiptir. YYBÜ aktif sürveyans yöntemiyle enfeksiyon kontrol komitesi tarafından takip edilmekte ve veriler düzenli olarak kaydedilmektedir. Araştırma süresi içinde YYBÜ'de takip edilen tüm yenidoğanlar çalışmaya alındı. Ancak bir günden daha kısa süre takip edilen bebekler ve/veya kolonize yenidoğanlar çalışmadan dışlandı.

Enfeksiyon sürveyans tanısı için Center for Diseases Control and Prevention (CDC) ve Ulusal Hastane Enfeksiyonları Sürveyans Ağının kriterleri baz alınarak SBiE tanısı konuldu (11, 12). KNS gibi cilt flora bakterileri ürediğinde, bebeğin kliniği değerlendirildi ve enfeksiyon bulgusu olmayan ve/veya akut faz reaktanları artmayan bebeklerdeki kan kültürü üremeleri enfeksiyon olarak değerlendirilmedi (13). Ayrıca kan kültürü iki set halinde alındı ve kültürlerden sadece birinde üreme olması ve/veya bebekte uygun klinik olmaması kontaminasyon olarak yorumlandı.

Veriler, SPSS 21 programında analiz edildi. SBIE hızının hesaplanmasında, takip edilen dönemde "gelişen SBIE sayısı/ yatan hasta sayısı X 100" formülü kullanıldı. İnvaziv araç ilişkili enfeksiyon hız hesaplanmasında; takip edilen dönemde 
"gelişen invaziv ilgili araç ilişkili enfeksiyon sayısı/ilgili araç günü X 1000" formülü kullanıldı.

\section{BULGULAR}

Bu araştırmada 2196 hasta, 33652 hasta günü izlendi. Hastaların 4157 ventilatör günü, 3343 umbilikal kateter günü, 5210 santral venöz kateter günü ve 92 üriner kateter günü saptandı. Tüm araştırma yılları için ortalama SBIE hızı \%4.78 (105/2196) ve insidans dansitesi \%3.12 (105/33652)'di (Tablo I, Şekil 1). SBIE hızı >2500 gr olan yenidoğanlarda düşük (\%1.02) iken 751-1000 gr arası yenidoğanlarda yüksek (\%23.95) saptandı $(p<0.001)$. Kiloya göre SBIE değerlendirildiğinde $\leq 750 \mathrm{gr}$ bebeklerin oranı (\%8.47) >2500 gr bebeklerinkine göre (\%1.02) anlamlı derecede yüksekti ( $\mathrm{p}<0.001)$ (Tablo II).
SBIE dağlımları değerlendirildiğinde; SBIE'nin 101(\%96.1)'i KDE, ikisi (\%1.90) pnömoni, biri (\%0.95) merkezi sinir sistemi enfeksiyonu ve biri (\%0.95) yumuşak doku enfeksiyonuydu (Tablo II).

Olgularda üretilen etkenler değerlendirildiğinde; bakterilerin \%59.0 (62/105)'u GNB ve \%41.0 (43/105)'i GPB'di (Șekil 2). En sık izole edilen GNB'ler; Klebsiella spp. (\%34.2) ve Enterobacter spp. (\%12.3) iken en sık GPB'ler ise koagülaz negatif stafilokoklar (\%26.6) ve S. aureus (\%10.4)'dü (Tablo IV).

İnvaziv araç ilişkili enfeksiyon hızları değerlendirildiğinde; santral venöz kateter ilişkili kan dolaşımı enfeksiyon hızı \%०0.95 iken umbilikal kateter ilişkili kan dolaşımı enfeksiyon hızı \%.2.09'du. Olgularımızda ventilatör ilişkili pnömoni ile kateter ilişkili üriner sistem enfeksiyonu saptanmadı.

Tablo I: Yıllara göre sağlık bakım ilişkili enfeksiyon hızı ve insidans dansitesi.

\begin{tabular}{l|c|c|c|c|c}
\hline \multicolumn{1}{r}{ Yıllar } & Yatan Hasta & Hasta Günü & Enfeksiyon $(\mathbf{n})$ & SBiE Hızı \% & İnsidans Dansitesi \%o \\
\hline $\mathbf{2 0 1 3}$ & 394 & 5.142 & 20 & 5.08 & 3.89 \\
$\mathbf{2 0 1 4}$ & 334 & 5.862 & 6 & 1.79 & 1.02 \\
$\mathbf{2 0 1 5}$ & 375 & 5.372 & 15 & 4.00 & 2.79 \\
$\mathbf{2 0 1 6}$ & 377 & 5.661 & 21 & 5.57 & 3.70 \\
\hline $\mathbf{2 0 1 7}$ & 332 & 5.854 & 22 & 6.62 & 3.75 \\
\hline $\mathbf{2 0 1 8}$ & 384 & 5.761 & 21 & 5.46 & 3.64 \\
\hline
\end{tabular}

SBiE: Sağllk bakım ilișkili enfeksiyon

Tablo II: 2013-2018 Yılları arasında yenidoğan yoğun bakım ünitesinde yatan bebeklerin doğum ağırlıklarına göre sağlık bakım enfeksiyonu gelişme durumları.

\begin{tabular}{|c|c|c|c|}
\hline \multirow{2}{*}{ Ağırlık } & \multicolumn{2}{|c|}{ Sağlık Bakım İlişkili Enfeksiyon } & \multirow{2}{*}{ Toplam n (\%)*^ } \\
\hline & Gelişen n (\%)* & Gelişmeyen n (\%)* & \\
\hline$\leq 750 \mathrm{gr}$ & $10(8.47)$ & $108(91.53)$ & $118(5.37)$ \\
\hline $751-1000 \mathrm{gr}$ & $23(23.96)$ & $73(76.04)$ & $96(4.37)$ \\
\hline $1001-1500 \mathrm{gr}$ & $36(13.48)$ & 231 (86.52) & $267(12.16)$ \\
\hline $1501-2500 \mathrm{gr}$ & $26(3.52)$ & $713(96.48)$ & 739 (33.65) \\
\hline$>2500 \mathrm{gr}$ & $10(1.02)$ & 966 (98.98) & $976(44.45)$ \\
\hline Toplam & $105(4.78)$ & 2091 (95.22) & $2196(100.0)$ \\
\hline
\end{tabular}

* Satır yüzdesi, ** Sütun yüzdesi, Ki kare değeri= 158.332 (p değeri < 0.001), Cramer V katsayısı=0.269 (p değeri <0.001)

Tablo III: Sağlık bakım ilişkili enfeksiyonların enfeksiyonlara göre dağıımı.

\begin{tabular}{|l|c|c|c|c|c|}
\hline \multicolumn{1}{|c|}{ Enfeksiyonlar } & Yatan Hasta & Hasta Günü & Enfeksiyon (n) & SBiE Hızı \% & İnsidans Dansitesi \%o \\
\hline Kan Dolaşımı Enfeksiyonu & 2196 & 33652 & 101 & 4.59 & 3.00 \\
\hline Pnömoni & 2196 & 33652 & 2 & 0.09 & 0.05 \\
\hline MSS Enfeksiyonu & 2196 & 33652 & 1 & 0.04 & 0.02 \\
\hline Yumuşak Doku Enfeksiyonu & 2196 & 33652 & 1 & 0.04 & 0.02 \\
\hline Üriner Sistem Enfeksiyonu & 2196 & 33652 & 0 & 0 & 0 \\
\hline
\end{tabular}

SBiE: Sağlık bakım ilişkili enfeksiyon, MSS: Merkezi sinir sistemi enfeksiyonu 
Tablo IV: Sağlık bakım ilişkili enfeksiyon etkenleri ve oluşturduğu klinik tablolar.

\begin{tabular}{|l|c|c|c|c|}
\hline \multicolumn{1}{|c}{ Mikroorganizmalar } & Etken $\%$ & $\mathbf{n}$ & Kültür Örneği & Klinik Tablo \\
\hline Klebsiella pneumoniae & 28.57 & 30 & Kan, DTA & Bakteriyemi, Pnömoni \\
\hline Koagülaz negatif stafilokok & 26.66 & 28 & Kan & Bakteriyemi \\
\hline Staphylococcus aureus & 10.47 & 11 & Kan, Yara & Bakteriyemi, YDE \\
\hline Enterobacter cloacae & 9.52 & 10 & Kan & Bakteriyemi \\
\hline Klebsiella oxytoca & 5.71 & 6 & Kan & Bakteriyemi \\
\hline Serratia marcescens & 5.71 & 6 & Kan & Bakteriyemi \\
\hline Pseudomonas aeruginosa & 3.80 & 4 & Kan & Bakteriyemi \\
\hline Enterobacter aerogenes & 2.85 & 3 & Kan & Bakteriyemi \\
\hline Escherichia coli & 2.85 & 3 & Kan, BOS & Bakteriyemi, Menenjit \\
\hline Enterococcus faecalis & 2.85 & 3 & Kan & Bakteriyemi \\
\hline Streptococcus spp. & 0.95 & 1 & Kan & Bakteriyemi \\
\hline
\end{tabular}

DTA: Derin trakeal aspirat kültürü, YDE: Yumuşak doku enfeksiyonu, BOS: Beyin omurilik sIVISI

\section{TARTIŞMA}

Bu araştırmada YYBÜ'de son altı yılda; 2014 yllında en düşük, 2017 yllında ise en yüksek oranda SBIE tespit edildi. Çalışma dönemi boyunca ortalama SBIE hızı \%4.78 (105/2196) ve insidans dansitesi \%o3.12 (105/33652) olarak saptandı. Enfeksiyon oranları ile insidans dansitesi koreleydi. Altı ylllık dönemde en sık saptanan bakteri Klebsiella pneumoniae ve en fazla tespit edilen SBIE ise KDE'di.

YYBÜ'de görülen SBiE hızları \%5-66 arasında bildirilmektedir. Prematüre bebek sayısındaki artışa paralel olarak YYBÜ'de izlenen hasta sayısı da artmakta ve düşük doğum ağırlıklı bebekler yaşatımaya çalışılmaktadır. Hastaların uzun süre yatıııması, invaziv girişimler, düşük doğum ağırlığı, total parenteral beslenme ve doğumsal anomaliler enfeksiyon riskini artırmaktadır (20). Yenidoğanlarda immün sisteminin gelişmemiş olması da SBIE gelişebilmesini kolaylaştııı (15). Bu araştırmada SBIE gelişme hızı, doğum ağırlığı ile ters orantıı olarak bulundu. SBIE en fazla $1000 \mathrm{gr}$ ve altındaki bebeklerde, en az 2500 gr üstü bebeklerde görülmüştür. Bu nedenle doğum ağırlığı düşük yenidoğanlarda enfeksiyon kontrol önlemleri daha özenli bir şekilde uygulanmalıdır. Bir araştırmada düşük doğum ağırlıklı yenidoğanlarda sepsis sıklığı \%43 iken; 2500 gr üstü yenidoğanlarda \%0.7 olarak bildirilmiștir (22). Çalıșmamızda da düşük doğum ağırlıklı yenidoğanlarda sık SBIE saptanması, literatürle uyumludur.

YYBÜ'de enfeksiyon kontrolünü sağlamak için ciddi önlemler gerekir. Ancak tüm çaba ve önlemlere rağmen yine de enfeksiyon gözlenebilmektedir. Yenidoğanların beslenmesi ve tedavi amaçlı santral venöz girişimlere bağlı KDE sıktır $(9,14,17,21)$. Bu araştırmada KDE en sık görülen enfeksiyondu. Başka merkezlerde yapılan araştırmalarda benzer sonuçlar söz konusudur $(15,16)$. Fas'ta yapılan bir çalışmada incelenen 702 yenidoğanın 91'inde nozokomiyal enfeksiyon (\%13) gelişmiş ve insidans yoğunluğu 1000 hasta günü başına 21.2 olarak saptanmış ve enfeksiyonlar içinde de en fazla \%89 ile KDE gözlenmiştir (20).

Çalsşmamızda yenidoğan pnömonisinin az görülmesi, hastalarda mekanik ventilatör kullanımının düşük olmasına bağlı olabileceği gibi CDC tarafından getirilen yeni tanı kriterlerine göre; ventilasyon cihazı ile ilgili tanımlamalardan da

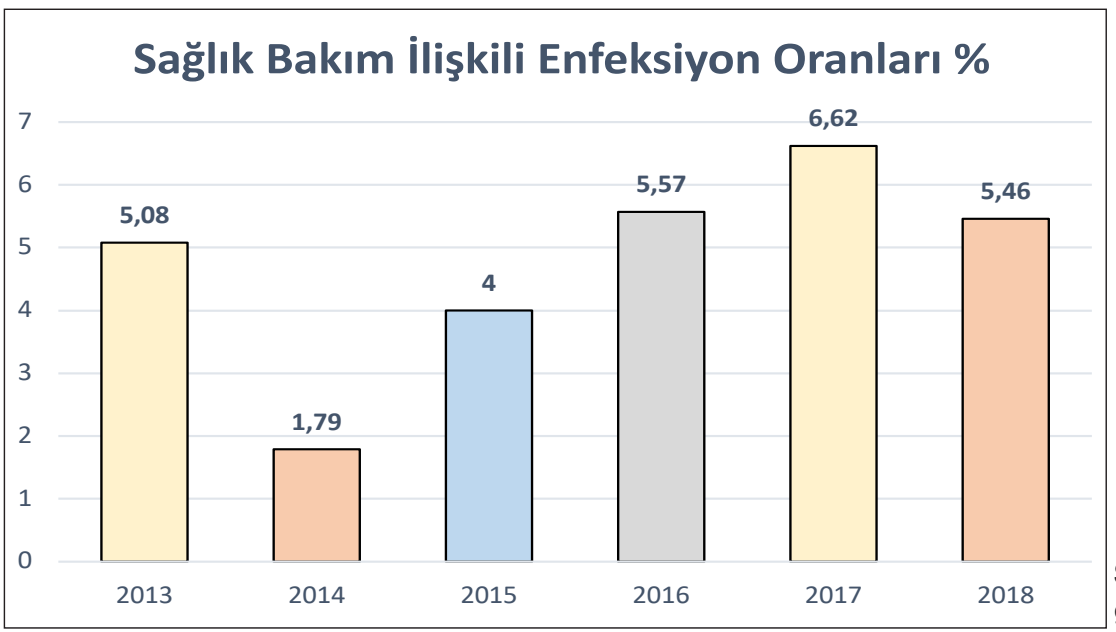

Şekil 1: Yıllara göre yenidoğan yoğun bakım ünitesinde gelişen sağlık bakım ilişkili enfeksiyon oranları. 


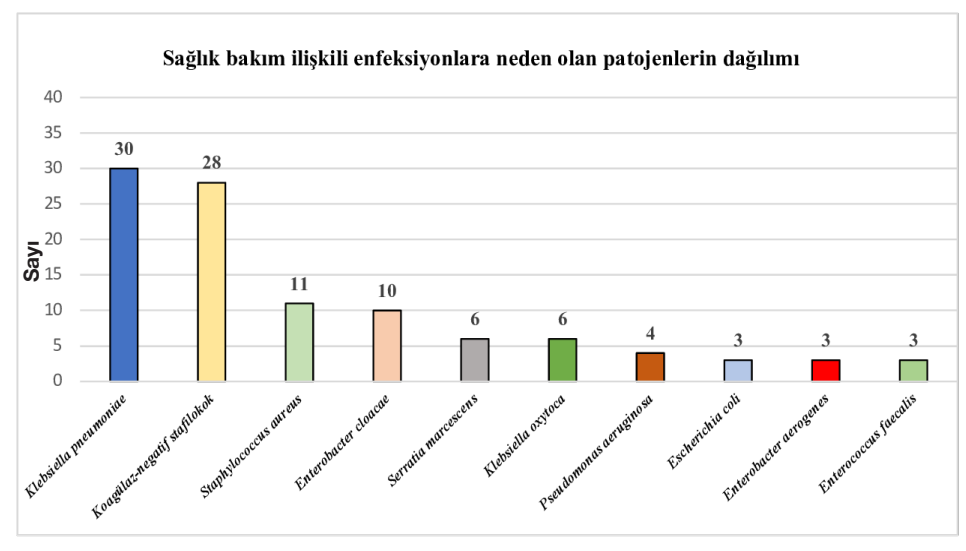

Şekil 2: Sağlık bakım ilişkili enfeksiyona neden olan patojenlerin dağılımı.

kaynaklanıyor olabilir. Ayrıca bronkoskopik örnekleme ya da derin trakeal aspirat gibi solunum örneklerinin kan kültürlerine göre daha az alınıyor olması da bu sonuçlarda etkili olabilir. Yine ünitemizde uzun süreden beri pnömoni önleme demetlerinin kullanılıyor olması da düşük pnömoni oranına katkı sağladığını düşünüyoruz.

Yıllara göre enfeksiyon yoğunluğuna bakıldığında; en yoğun yatışın yaşandığı (dansite \%o3.75) 2017 yılında en fazla enfeksiyon tespit edilirken (\%62) en düşük yoğunluğun yaşandığı 2014'te en az enfeksiyon saptandı. Ancak 2014 yılında oluşan salgın nedeniyle üniteye hasta alımı enfeksiyon kontrol komitesi kararıyla kısıtlandı. Bu nedenle 2014 yılında yoğunluk en azdı. Üniteye hasta alımının durdurulması ünitede çalışan tüm sağıı personelinde aşırı duyarlılık oluşturdu. Bu nedenle el hijyeninden ünite hijyenine kadar tüm enfeksiyon kontrol tedbirlerine titizlikle uyumun artması bu dönemdeki enfeksiyon hızlarındaki düşmede etkili olduğunu düşünüyoruz.

YYBÜ'de, son 10 yılda SBIE'lerine neden olan patojenler Şekil 2'de sunulmuştur. Çalışma döneminde YYBÜ'de en sık SBIE etkeni GNB (\%59.0) ve en fazla SBIE etkeni olan patojen ise K.pneumoniae'di (\%34.2). Bir başka araştırmada SBIE enfeksiyon etkeni olarak izole edilen patojen mikroorganizmaların en fazla GNB (\%79.8) olduğunu ve en fazla izole edilen GNB'nin K.pneumoniae (n:22 \%29.3) olduğunu bildirildi (18). Yine başka bir çalışmada, en fazla SBIE etkenlerinin GNB (\%54.4) ve en fazla etkenin de K.pneumoniae (\%19.6) olduğunu tespit ettiler (19). Maoulainine ve ark.(20), SBiE'nin \%79.6'sının ESBL üreten GNB olduğunu ve en fazla SBIE neden olan patojenin K.pneumoniae (\%39.7) olduğunu bildirdiler. Sonuçlarımız literatürle uyumludur.

Sonuç olarak yıllar içinde YYBÜ en sık gözlediğimiz enfeksiyonlar KDE, en sık saptadığımız etken de K. pneumoniae'idi. YYBÜ'de KDE sıklığını azaltacak enfeksiyon kontrol tedbirleri titizlikle uygulanmalı, personel eğitimleri ve enfeksiyon sıklığı düzenli aralıklarla gözden geçirilmelidir.

\section{KAYNAKLAR}

1. Kumar S, Shankar B, Arya S, Deb M, Chellani H. Healthcare associated infections in neonatal intensive care unit and its correlation with environmental surveillance. Journal of Infection and Public Health 2018;11:275-9.

2. Chen YC, Lin CF, Rehn YJF, Chen JC, Chen PC, Chen $\mathrm{CH}$, et al. Reduced nosocomial infection rate in a neonatal intensive care unit during a 4-year surveillance period. J Chin Med Assoc 2017;80:e427-31.

3. Mohammed D, El Seifi SO. Bacterial nosocomial infections in neonatal intensive care unit, Zagazig University Hospital Egypt. Egyptian Pediatric Association Gazette 2014;62:72-79.

4. Bowen JR, Callander I, Richards R, Lindrea KB. Decreasing infection in neonatal intensive care units through quality improvement. Arch Dis Child Fetal Neonatal Ed 2017;102:F51-F57.

5. Djordjevic ZM, Markovic-Denic L, Folic MM, Igrutinovic Z, Jankovic SM. Healthcare Acquired infections in neonatal intensive care units: Risk factors and etiology. Am J Infect Control 2015;43:86-8.

6. Sultan AM, Seliem WA. Identifying Risk Factors for HealthcareAssociated Infections Caused by Carbapenem-Resistant Acinetobacter baumannii in a Neonatal Intensive Care Unit. Sultan Qaboos Univ Med J 2018;18:e75-e80.

7. Parlak E, Kahveci H, Alay HK. Yenidoğan Yoğun Bakım Ünitesindeki Hastane Enfeksiyonları. Güncel Pediatri 2014;1:1-8.

8. Sadeghi-Moghaddam S, Arjmandnia M, Shokrollahi M, Aghaali M. Does training improve compliance with hand hygiene and decrease infections in the neonatal intensive care unit? A prospective study. J Neonatal Perinatal Med 2015;8:221-5.

9. Huang YC. Device-associated Healthcare-associated Infections in the Neonatal Intensive Care Unit. Pediatr Neonatol 2013;54:e2934.

10. Garcia H, Torres-Gutierrez J, Peregrino-Bejarano L, CruzCastaneda MA. Risk factors for nosocomial infection in a level III. Gac Med Mex 2015;151:660-8.

11. Dramowski A, Madide A, Bekker A. Neonatal nosocomial bloodstream infections at a referral hospital in a middle-income country: burden, pathogens, antimicrobial resistance and mortality. Paediatr Int Child Health 2015;35:265-72.

12. https://dosyaism.saglik.gov.tr/Eklenti/15719, ulusal-saglik-hizmetiilişkili-enf-sürveyans-rehberipdf.pdf?0, ET: 06.07.2019, 20:06 
13. Satar M, Arısoy AE, Çelik IH. Turkish Neonatal Society guideline on neonatal infections-diagnosis and treatment. Turk Pediatri Ars 2018; 25;53 (Suppl 1):S88-S100.

14. Mobley RE, Bizzarro MJ. Central line-associated bloodstream infections in the NICU: Successes and controversies in the quest for zero. Seminars in Perinatology 2017;41:166-74.

15. Stoll BJ, Hansen N, Fanaroff AA, Wright LL, Carlo WA, Ehrenkranz $\mathrm{RA}$, et al. Late-onset sepsis in very low birth weight neonates: the experience of the NICHD Neonatal Research Network. Pediatrics 2002;110:285-91.

16. Stoll BJ, Gordon T, Korones SB, Shankaran S, Tyson JE, Bauer $\mathrm{CR}$, et al. Early-onset sepsis in very low birth weight neonates: a report from the National Institute of Child Health and Human Development Neonatal Research Network. J Pediatr 1996;129:7280.

17. Pogorzelska-Maziarz M, The Use and Effectiveness of Bundles for Prevention of Central Line-Associated Bloodstream Infections in Neonates: A Review of the Literature. J Perinat Neonatal Nurs 2016;30:148-59.

18. Balaban I, Tanır G, Timur OM, Oz FN, Teke TA, Bayhan Gl, et al. Nosocomial Infections in the General Pediatric Wards of a Hospital in Turkey, Jpn. J Infect Dis 2012; 65:318-21.

19. Mai JY, Dong L, Lin ZL, Chen SQ. Investigation and analysis of nosocomial infection in neonates. Zhonghua $\mathrm{Er} \mathrm{Ke} \mathrm{Za} \mathrm{Zhi.}$ 2011;49:915-20.

20. Maoulainine FM, Elidrissi NS, Chkil G, Abba F, Soraa N, Chabaa L, et al. Epidemiology of nosocomial bacterial infection in a neonatal intensive care unit in Morocco. Arch Pediatr 2014;21:938-43.

21. Tseng YC, Chiu YC, Wang JH, Lin HC, Lin HC, Su BH, et al. Nosocomial bloodstream infection in a neonatal intensive care unit of a medical center: a three-year review. J Microbiol Immunol Infect. 2002;35:168-72.

22. Dowey LC, Smith PB, Benjamin DK Jr. Risk factors and prevention of late-onset sepsis in premature infants. Early Hum Dev 2010;86 Suppl 1:7-12. 